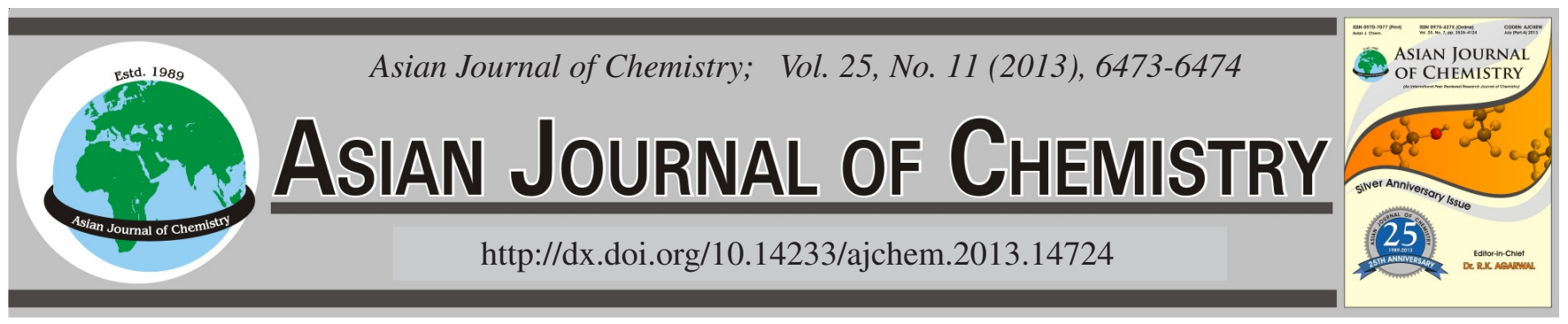

NOTE

\title{
Optimization of Synthesis Technology of Azelaic Acid by Orthogonal Test
}

\author{
Pinghua Zhu*, Wang LeI and Shuoran Zeng
}

Department of Chemical Engineering, Huaihai Institute of Technology, Lianyungang 222005, P.R. China

*Corresponding author: Tel: +86 13961323933; E-mail: lygzph@163.com

\begin{abstract}
Azelaic acid was synthesized by using 1,5-neopentyl glycol and phosphorus tribromide as raw materials and pyridine as catalyst. Orthogonal test was adopted to ensure the first optimum synthesis conditions of reaction time, $2 \mathrm{~h}$; pyridine as catalyst, $1.0 \mathrm{~g}$; reaction temperature, $60{ }^{\circ} \mathrm{C}$. The total recovery of products, $91.6 \%$; content, $98.5 \%$; the results of variance component show that reaction temperature is the main influencing factor.
\end{abstract}

Key Words: Synthesis, Orthogonal test, Azelaic acid.

Azelaic acid is an important intermediate of organic synthesis. More than $70 \%$ of azelaic acid derivatives are used to synthesize DOZ plasticizer and then fragrance, lubricating oil, oiling agent, polyamide resin and other products ${ }^{1}$. Due to DOZ's cold resistance is better than dioctyl adipate and smaller volatility, better ageing resistance, so the consumption rises day by day ${ }^{2,3}$. Now, the mode of production of azelaic acid is the oxidation process of linoleic acid and other unsaturated acids and the only industrialized production method in the world. Weiqun et al. ${ }^{3}$ have reported that their productivity of laboratory scale is $c a$. $45 \%$. Fangzhen ${ }^{4}$ has prepared azelaic acid by using potassium hypermanganate and TBAB from Chinese prickly ash seed oil soapstock, the productivity of crude product is (48-52)\%. We can also prepare azelaic acid by $\mathrm{Pt}$, other metal catalyzed oxidation of dihydric alcohol and metal catalyzed oxidation of dihydric aldehyde, its productivity is more than $80 \%$ but it has higher cost. The orthogonal test is an effective method of studying multiple factors and is adopted to apply widely in the scientific research but there are fewer applications and researches of the literature in the synthesis of azelaic acid ${ }^{5}$. The experiment adopts the orthogonal test of $\mathrm{L}_{9}(3)^{3}$ for studying that multiple factors have effects on its synthesis in order to find the optimum synthesis conditions.

1,5-Neopentyl glycol, phosphorus tribromide, pyridine, dimethyl malonate and potassium carbonate are of analytical grade reagents.

Orthogonal experimental design: On the basis of adopting 1,5-neopentyl glycol and phosphorus tribromide as raw materials and pyridine as catalytic to synthesize azelaic $\operatorname{acid}^{6}$ (SchemeI). In order to ensure the optimum technological conditions of reactions, we choose the orthogonal test table with Mimizu Hirami factor (Table-1), especially the main factors which influence its total recovery,such as reaction temperature, reaction time, the amount of catalysts etc. We conduct large numbers of experiments about them and ensure the optimum technological conditions of reactions.

$$
\begin{gathered}
\mathrm{HOH}_{2} \mathrm{C}\left(\mathrm{CH}_{2}\right)_{3} \mathrm{CH}_{2} \mathrm{OH}+\mathrm{PBr}_{3} \rightarrow \mathrm{BrH}_{2} \mathrm{C}\left(\mathrm{CH}_{2}\right)_{3} \mathrm{CH}_{2} \mathrm{Br}+ \\
\mathrm{C}_{5} \mathrm{H}_{8} \mathrm{O}_{4} \rightarrow \mathrm{C}_{15} \mathrm{H}_{24} \mathrm{O}_{8}+\mathrm{H}_{2} \mathrm{O} \rightarrow \mathrm{HOOC}\left(\mathrm{CH}_{2}\right)_{7} \mathrm{COOH}
\end{gathered}
$$

Scheme-I: Synthetic route

\begin{tabular}{cccc}
\multicolumn{5}{c}{ TABLE-1 } \\
\multicolumn{2}{c}{$\mathrm{L}_{9}(3)^{3}$} & ORTHOGONAL EXPERIMENTAL DESIGN OF HEADER \\
\hline \multirow{2}{*}{ Level } & $\begin{array}{c}\text { Reaction } \\
\text { time A }(\mathrm{h})\end{array}$ & $\begin{array}{c}\text { Amount of } \\
\text { catalysts B }(\mathrm{g})\end{array}$ & $\begin{array}{c}\text { Reaction temperature } \\
\mathrm{C}\left({ }^{\circ} \mathrm{C}\right)\end{array}$ \\
\hline 1 & 1 & 0.5 & 50 \\
2 & 2 & 1.0 & 70 \\
3 & 3 & 1.5 & 60 \\
\hline
\end{tabular}

Synthetic method: Above all, we need to titrate pentanediol $10.4 \mathrm{~g}$, pyridine $1 \mathrm{~g}$, phosphorus tribromide $10.4 \mathrm{~g}$ in the flask and produce the fog at the same time and the temperature reaches $30^{\circ} \mathrm{C}$ now. Then, the temperature slowly rises to $40{ }^{\circ} \mathrm{C}$ and the solution will be cooled by cold water. The temperature can't more than $40^{\circ} \mathrm{C}$ and the solution colour is yellowish white. The solution is heated to $60{ }^{\circ} \mathrm{C}$ after the titration and stirred for $2 \mathrm{~h}$ under the constant temperature. It is washed by the distilled water 4 times when the reaction is finished, then is separated by the separating funnel, the product is yellow and dried by adding anhydrous sodium carbonate. 
Firstly, the 1,5-pentamethylene dibromide, dimethyl malonate and potassium carbonate put in the flask with three necks and heated for $2 \mathrm{~h}$, the temperature should not be more than $60^{\circ} \mathrm{C}$. When the reaction starts, the solution is a yellowish white. The rest of dimethyl malonate in the solution needs to be steamed out after the reaction and the solution is a pale orange paste.

First of all, the solution of sodium hydrate $(300 \mathrm{~mL})$ needs to be added in the solution and refluxed for $4-5 \mathrm{~h}$, then it is pale red transparent liquid when it begins to reflux and the $\mathrm{pH}$ will be regulated to 4 by adding $\mathrm{HCl}$. The water of the solution needs to be dried with the rotary evaporator and the yellow substance appears; next, the alcohol should be added to dissolve and extract. Finally, the alcohol evaporated out and the yellow crystal appears.

Analysis of products: m.p. $104-107^{\circ} \mathrm{C}$ (literature) (105$\left.106^{\circ} \mathrm{C}\right)^{7}$. The content of the product which is analyzed by the high performance liquid chromatography is $98.5 \%$. The results of infrared spectral analysis test are as followed $(\mathrm{KBr}$ pellet technique).

The strong and broad characteristic absorption peak appears in the scope of $3100-2400 \mathrm{~cm}^{-1}$, the strong absorption peak of $\mathrm{COOH}$ appears in the scope of $1700 \mathrm{~cm}^{-1}$ and the absorption peak of $\mathrm{C}-\mathrm{H}$ of $2935 \mathrm{~cm}^{-1}$, which shows that the relative amount of $\mathrm{COOH}$ rises. In addition, the characteristic absorption peaks of $\mathrm{C}-\mathrm{O}, \mathrm{O}-\mathrm{H}, \mathrm{C}=\mathrm{O}$ also appear, which proves the existence of azelaic acid.

Factors associated with orthogonal test table.

Test results of range analysis: The results of orthogonal experiment sees the productivity as the main exploration target and the higher the productivity, the better the result. The range of all treatment combinations: The relation of the reaction time $\left(\mathrm{R}_{\mathrm{A}}\right) 4.2$, the amount of catalysts $\left(\mathrm{R}_{\mathrm{B}}\right) 5.3$ and reaction temperature $\left(R_{C}\right) 6.2$ is $R_{C}>R_{B}>R_{A}$. It is noted that factor $C$ that is the reaction temperature among three factors has the most important effects on the productivity and the next is the amount of catalysts.

Influence of all reaction factors and the option of the optimum plan: Table- 2 showed that the suitable temperature is $c a .60^{\circ} \mathrm{C}$. Although the rise of the temperature is of help to speed up the reaction, this will be likely to reduce the yield of product $^{8}$; the suitable total reaction time is $2 \mathrm{~h}$. Conbined with the result of range analysis, the reaction temperature chooses the optimal level. On the basis of the thrift and convenience to ensure the optimum plan $\mathrm{A}_{2} \mathrm{~B}_{2} \mathrm{C}_{3}$ for the inferior factor such as the amount of catalysts under the condition of the reaction time $(2 \mathrm{~h})$, the amount of catalysts $(1 \mathrm{~g})$, the reaction temperature $\left(60^{\circ} \mathrm{C}\right)$ the highest productivity. The conbined plan needs to be repeated for three times, the productivity is between 89 and $91 \%$ and it has the better repeatability (Table-3).
TABLE-2

THREE FACTORS AND THREE LEVELS ORTHOGONAL DESIGN AND EXPERIMENTAL RESULTS

\begin{tabular}{ccccc}
\hline No. & $\begin{array}{c}\text { Reaction } \\
\text { time (h) A }\end{array}$ & $\begin{array}{c}\text { The amount of } \\
\text { catalysts }(\mathrm{g}) \mathrm{B}\end{array}$ & $\begin{array}{c}\text { Temperature } \\
\left({ }^{\circ} \mathrm{C}\right) \mathrm{C}\end{array}$ & $\begin{array}{c}\text { Productivity } \\
(\%)\end{array}$ \\
\hline 1 & A1 & B1 & C1 & 75.8 \\
2 & A1 & B2 & C2 & 78.6 \\
3 & A1 & B3 & C3 & 81.6 \\
4 & A2 & B1 & C2 & 77.0 \\
5 & A2 & B2 & C3 & 91.6 \\
6 & A2 & B3 & C1 & 81.4 \\
7 & A3 & B1 & C3 & 80.5 \\
8 & A3 & B2 & C1 & 79.8 \\
9 & A3 & B3 & C2 & 78.9 \\
\hline
\end{tabular}

TABLE-3

\begin{tabular}{cccc}
\multicolumn{4}{c}{ TABLE-3 } \\
RESULTS OF RANGE ANALYSIS \\
\hline & $\begin{array}{c}\text { Reaction } \\
\text { time }(\mathrm{h}) \mathrm{A}\end{array}$ & $\begin{array}{c}\text { Amount of } \\
\text { catalysts }(\mathrm{g}) \mathrm{B}\end{array}$ & $\begin{array}{c}\text { Reaction temperature } \\
\left({ }^{\circ} \mathrm{C}\right) \mathrm{C}\end{array}$ \\
\hline $\mathrm{K} 1 \mathrm{j}$ & 78.7 & 77.8 & 79.0 \\
$\mathrm{~K} 2 \mathrm{j}$ & 83.4 & 83.3 & 78.2 \\
$\mathrm{~K} 3 \mathrm{j}$ & 79.7 & 80.6 & 84.6 \\
$\mathrm{R}$ & 4.7 & 5.5 & 6.4 \\
\hline
\end{tabular}

\section{Conclusion}

Optimize the manufacturing process of using the phase transfer catalysis to synthesize azelaic acid by the orthogonal test $\mathrm{L}_{9}(3)^{3}$ to find out the main influencing factor and the optimum manufacturing process: the reaction time $(2 \mathrm{~h})$, the amount of catalysts $(1 \mathrm{~g})$, the reaction temperature $\left(60^{\circ} \mathrm{C}\right)$. The result of the range experiment shows that the reaction temperature and the amount of catalysts are the main influencing factor.

\section{ACKNOWLEDGEMENTS}

This article is financially supported 2013 Annual Students' Practical and Innovative Training Program

\section{REFERENCES}

1. World Handbook of Fine Chemical Industry (Continuation), Yu Maozhang (1970), Ministry of Chemical Industry Institute of Science and Technology Information, Beijing, pp. 12/1088-12/1089 (1986).

2. Z.Y. Gu and W.M. Hu, J. Speciality Petrochem., 6, 40 (1998).

3. W.Q. Gian, Z.Y. Huang and N.J. Zhu, J. Fine Chem., 11, 56 (1994).

4. F.Z. Liang, J. Chin. Oil, 22, 43 (1994).

5. H. Ma, Chemical Experiment Technique (II), (1968), Chemical Industry Press, Beijing, pp. 2/35-2/48 (2002).

6. N.T. Fan, Organic Synthesis Encyclopedia (1966), Beijing Institute of Technology Press, Beijing, pp. 8/294-8/295 (1992).

7. H.Y. Song, J. Petroleum Chem. Ind., 33, 1608 (2004).

8. F. Sun, J. Contemporary Chem. Ind., 41, 455 (2012). 